
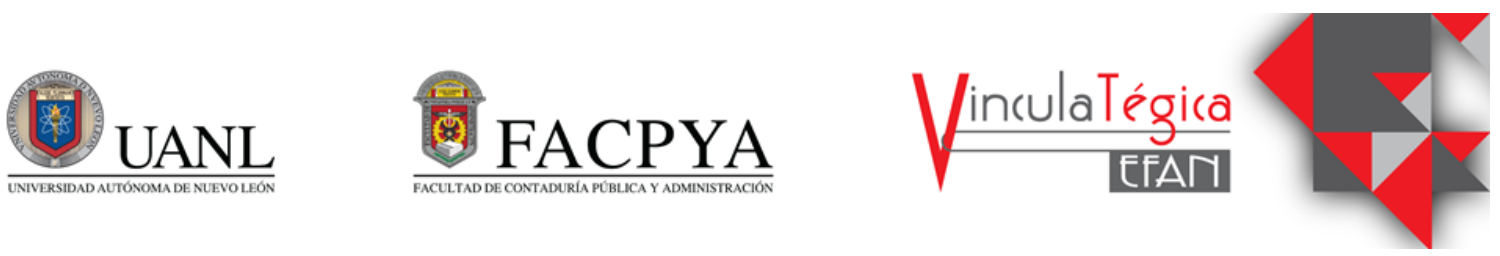

\title{
La importancia en la acreditación sanitaria de un laboratorio de análisis químico de alimentos
}

\author{
Adolfo B. Montaño-Hernández ${ }^{1}$ y Juan B. Vela Reyna ${ }^{2}$ \\ ${ }^{1}$ Universidad Autónoma de Baja California, adolfo.montano@uabc.edu.mx, Boulevard Río Nuevo y Eje \\ Central s/n, C.P. 21330, 21330 Mexicali, Baja California, (686)582 3377 \\ ${ }^{2}$ Universidad Autónoma de Baja California, jbenitovela@uabc.edu.mx, Boulevard Río Nuevo y Eje Central \\ s/n, C.P. 21330, 21330 Mexicali, Baja California, (686)582 3377
}

IInformación del artículo revisado por pares

Fecha de aceptación: junio-2021

Fecha de publicación en línea: diciembre-2021

DOI: https://doi.org/10.29105/vtga7.2-41

\section{Resumen}

El presente análisis de investigación presenta la Importancia en la Acreditación de Laboratorios que ofrece el servicio de análisis químico de alimentos y productos industriales. Sin la existencia de estos Laboratorios Bromatológicos Acreditados, no habría la suficiente calidad y salubridad necesaria para llevar un control en todo lo que se consume, por ende, existiría un mayor número de virus, enfermedades y mortandad. La EMA (Entidad Mexicana de Acreditación), señaló que los laboratorios que cuentan con la respectiva acreditación le pueden otorgar mayor confiabilidad y hacerlos sentir más seguros a sus clientes sobre los productos y servicios que se les ofrece, también se dispone con análisis muy minuciosos que evalúan la exigencia que está ofreciendo algún Laboratorio en el cual se les exige altos estándares de calidad y salud.

Palabras Clave: Análisis Químico, Laboratorios Acreditados, Crecimiento Económico.

\begin{abstract}
This research analysis presents the Importance in Laboratory Accreditation offered by the chemical analysis service of food and industrial products. Without the existence of these Accredited Bromatological Laboratories, there would not be the sufficient quality and health necessary to keep track of everything that is consumed, therefore, there would be a greater number of viruses, diseases and mortality. The EMA (Mexican Accreditation Entity) noted that laboratories that have the respective accreditation can give them greater reliability and make them feel safer to their customers about the products and services offered to them, also has very thorough analyses that evaluate the requirement that a Laboratory is offering in which they are required high standards of quality and health.
\end{abstract}

Keywords: Chemical Analysis, Accredited Laboratories, Economic Growth 


\section{INTRODUCCIÓN}

EMA (2015) señala que La Entidad Mexicana de Acreditación (EMA), es la primera entidad de gestión privada en nuestro país, que tiene como objetivo acreditar a los Organismos de la Evaluación de la Conformidad que son los Laboratorios de Ensayo, entre otros. EMA cuenta con la autorización de Buenas Prácticas de Laboratorio de la Organización para la Cooperación y el Desarrollo Económico (OCDE).

EMA (2015) señala que cuenta con los máximos reconocimientos internacionales por el Foro Internacional de Acreditación (IAF) y la Cooperación Internacional de Acreditación de Laboratorios (ILAC), y los foros regionales Cooperación de Acreditación de Asia Pacifico (APAC), la Cooperación Interamericana de Acreditación (IAAC), lo anterior confirma que la EMA trabaja con apego a las normas nacionales e internacionales. EMA también ha sido galardonada con el Premio Ética y Valores en varias ediciones, este premio lo otorga la Confederación de Cámaras de Industriales de los Estados Unidos Mexicanos (CONCAMIN).

El Proceso de Acreditación por medio de la EMA es complejo y después de seguir varios pasos. El Laboratorio al cual necesita acreditarse tiene que estar en funcionamiento (aunque no esté acreditado) para que la EMA visite dicho lugar; el laboratorio tiene que cubrir los costos que genere dicha acreditación, así como los gastos de viaje del acreditador y de un acompañante. El proceso de acreditación es de aproximadamente 10 meses.

ProquiDeza (2015) señala que un laboratorio acreditado es aquel que cuenta con el reconocimiento oficial de su competencia, este reconocimiento consigue que los clientes tengan una forma rápida de seleccionar servicios garantizados para pruebas, medición y calibraciones.

La idea de crear un Laboratorio Acreditado que ofrezca el servicio de análisis químico de alimentos y productos industriales nace por el hecho de no tener la suficiente certidumbre o claridad del tipo de alimento y, sobre todo, de qué calidad está ingiriendo el consumidor ese mismo alimento.

Al tener un análisis químico de un Laboratorio Acreditado, el producto podrá elevar su presencia en el mercado, tener mayor certidumbre y elevar su precio y calidad como producto.

La finalidad del laboratorio de análisis químicos de alimentos es proporcionar información sobre la composición de estos. Haciendo énfasis en la calidad y la garantía de la calidad.

Para juzgar la calidad de esa información hay que tener en cuenta si alcanza el nivel apropiado, si se facilita oportunamente y si se produce con un costo aceptable.

El criterio para determinar si "se alcanza el nivel apropiado" consiste en que los datos sean o no idóneos para el fin al que están destinados.

The Quality Manual: Guidance for Preparation (1989) señala que la garantía de la calidad es el sistema que proporciona confianza en que:

- Se ha alcanzado un nivel suficiente.

- Se detectarán los casos en que no se alcance ese nivel.

- Podrán identificarse y corregirse las causas por las que no se ha alcanzado ese nivel

Díaz (2017) señala en el Manual del Laboratorio de Bromatología, la importancia en la acreditación de los laboratorios de análisis químico de alimentos para analizar de la manera más salubre y de mejor calidad los siguientes datos y en el orden en el cual aparecen desglosados:

1. Humedad

2. Materia Seca

3. Proteína Cruda 
4. Extracto Etéreo

5. Fibra Cruda

6. Carbohidratos

7. Minerales

La importancia de disponer con un Laboratorio Acreditado es para poder ofrecer un servicio a las empresas que necesitan contar con la seguridad en los resultados.

Actualmente nos encontramos ante una normativa y un mercado más exigente buscando servicios que le den a las empresas ese diferenciador a sus productos, por esa razón es que en el tema de calidad y salud es imprescindible elegir los servicios de un Laboratorio Acreditado que garantice resultados confiables.

\section{MARCO TEÓRICO}

Instituto Nacional de Estadística y Geografía por sus siglas INEGI (2020) hace hincapié en lo siguiente:

- La ECOVID-IE segunda edición estima que $86.6 \%$ de $1873 \quad 564$ empresas en el país tuvieron alguna afectación a causa de la pandemia.

- La disminución de los ingresos fue el principal tipo de afectación que reportaron $79.2 \%$ de las empresas.

- De los 4.9 millones de establecimientos del sector privado y paraestatal registrados en los Censos Económicos 2019, 99.8\% pertenecen al conjunto de establecimientos micro, pequeños y medianos.

- A 17 meses de concluido el levantamiento censal, el Estudio sobre Demografía de los Negocios 2020 estima que, de los 4.9 millones de establecimientos micro, pequeños y medianos sobrevivieron 3.9 millones (79.19\%), poco más de un millón $(20.81 \%)$ cerraron sus puertas definitivamente.

\subsection{MARCO LEGAL}

La NOM 051 es de suma importancia ya que es la encargada de regular lo que comemos.

Valdés (2019) señala en Mi Salud Hoy con referencia en publicaciones realizadas por medio de la Secretaría de Salud que México está en el lugar número 1 a nivel mundial en obesidad infantil y el segundo en adultos, sobrepasando a Estados Unidos.

La gravedad de este tema es sumamente delicada y después que la Secretaría de Salud emitiera una emergencia por el alto porcentaje de obesidad en el país, el Congreso de la Unión emitió nuevas normas para regular la manera en que las empresas de la industria alimentaria y de bebidas etiquetaban sus productos, removiendo imágenes que incitaran a los niños a consumir productos que les proporcionaran obesidad infantil, entre otros padecimientos a largo plazo.

La razón para realizar dicho etiquetado es para tener más informado al consumidor de lo que realmente está consumiendo y apoyarlo a realizar mejores decisiones, ya que, es clara la preocupación para prevenir con anticipación el tema de la obesidad, pero este tema conlleva a otras enfermedades. Mejorando la manera en la que se consumen alimentos y bebidas, se tendrá una vida más sana y una mejor calidad de vida, ya que, la mayoría de las personas consumen alimentos y bebidas no para alimentarse, sino para llenarse.

La Secretaría de Economía por medio del Diario Oficial de la Federación (2009) señala que la NOM 051 tiene como objeto establecer la información comercial y sanitaria que debe contener el etiquetado de los alimentos y bebidas no alcohólicas pre envasados de fabricación nacional $o$ extranjera, así como determinar las características de dicha información. 
La información nutrimental puede presentarse de la siguiente manera conforme a lo indicado en la figura 1 :

Figura 1.- Presentación de la Información Nutrimental

\begin{tabular}{|l|c|}
\hline \multicolumn{1}{|c|}{ Información nutrimental } & $\begin{array}{c}\text { Por } 100 \mathrm{~g} \text { o } 100 \mathrm{ml} \text {, o por porción o } \\
\text { por envase }\end{array}$ \\
\hline Contenido energético $\mathrm{kJ}$ (kcal) & $\mathrm{kJ}(\mathrm{Kcal})$ \\
\hline Proteínas & $\mathrm{g} \mathrm{y} / \mathrm{o} \%$ de IDR \\
\hline Grasas & $\mathrm{g}$, de las cuales \\
& $\mathrm{g}$ de grasa saturada \\
\hline Carbohidratos (hidratos de carbono) & $\mathrm{g}$, de los cuales \\
\hline Sodio & $\mathrm{g} \mathrm{de}$ azúcar. \\
\hline Información adicional & $\mathrm{g} \circ \mathrm{mg}$ \\
\hline
\end{tabular}

La información mostrada en la figura 1, es un ejemplo de la información nutrimental con su respectiva porción que debe de contener una etiqueta después de realizar un análisis bromatológico en un laboratorio acreditado. Gracias a este tipo de etiquetas, el consumidor puede tener conocimiento de lo que está ingiriendo con su respectiva porción. La porción va a ir acorde al tipo de consumidor, por ejemplo, no se le puede recomendar la misma porción a un niño que a un adulto. Estas etiquetas son meramente como información y conocimiento al consumidor de lo que se está ingiriendo.

De igual manera la Secretaría de Economía (2009) indica que en la NOM 051 se desaprueba lo siguiente:

$>$ Declaración de propiedades

- Que al consumidor le haga suponer que lo que está consumiendo es un producto nutritivo, cuando no se tiene ningún análisis ni se puede comprobar dicha afirmación.

- Que al consumidor se le haga creer que lo que está consumiendo tiene efectos milagrosos, cuando no existe ninguna prueba que confirme dicha información.

- Que al consumidor se le haga llegar información que lo confunda sobre la inocuidad y calidad de dichos alimentos.

- Declaraciones que pueden influenciar en el error del consumidor
- Que al consumidor no se le informe del producto o que no tenga información completa.

- Que al consumidor se le afirme que está consumiendo un producto que no es, por ejemplo, que se le haga saber que está consumiendo un producto natural cuando en realidad no se cuenta con estudios o análisis al respecto.

- Que al consumidor se le haga saber que el producto que está consumiendo es un producto totalmente garantizado, cuando en realidad no se tienen análisis al respecto.

\section{MÉTODO}

La metodología cuantitativa utilizada para llegar a los resultados de dicha 
investigación a la que se hace mención en este artículo son las siguientes:

- Análisis Estadísticos y Correlacionados. Gracias a las diferentes herramientas proporcionadas por INEGI, se analizó la relación existente entre varias variables, por ejemplo, la oferta y demanda histórica en Laboratorios Acreditados.
La metodología cualitativa utilizada para llegar a los resultados de dicha investigación a la que se hace mención en este artículo son las siguientes:

- Entrevistas. Se entrevistaron a 40 empresarios, en el cual se llega a la conclusión que al $80 \%$ le urge corroborar la calidad de sus productos para poder incrementar sus ventas $\mathrm{y}$ tener mayor certidumbre.

\section{RESULTADOS}

Figura 2.- Oferta de Laboratorios en el año 2018

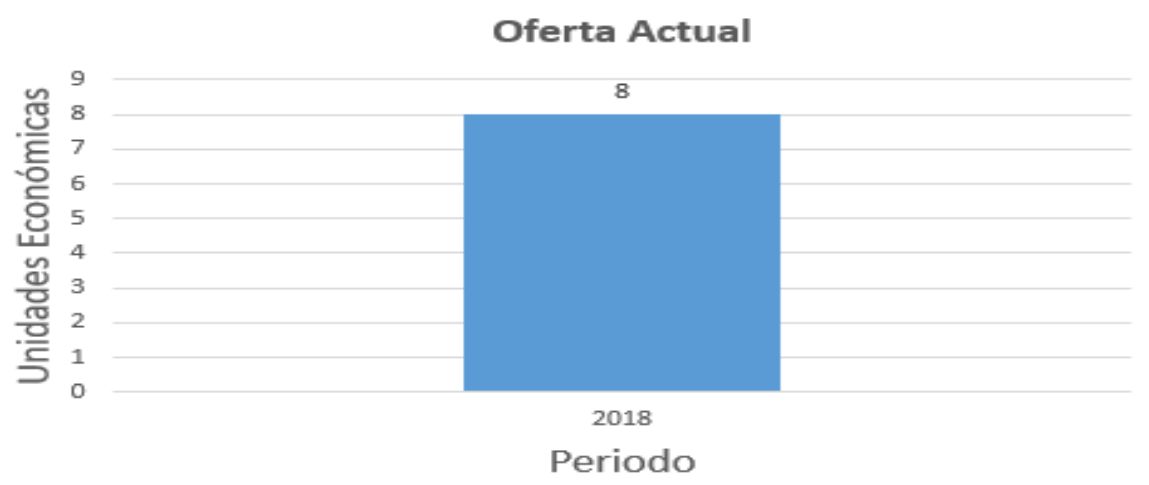

Las unidades económicas que ofertan el servicio de Laboratorio en la Ciudad de Mexicali son de 8 laboratorios en el año 2018.

Cabe resaltar que, de esos 8 laboratorios, ninguno oferta el servicio para análisis químico de alimentos y productos industriales. Siendo en su mayoría laboratorios clínicos, pero no se cuenta con laboratorios bromatológicos acreditados. Los 8 laboratorios son meramente como información de un área similar al que se quiere investigar.

La proyección de la oferta en la Ciudad de Mexicali, Baja California es la siguiente: 
Figura 3.- Proyección de la Oferta de Laboratorios en Mexicali, B.C.

\section{Unidades Económicas del 2003-2023}

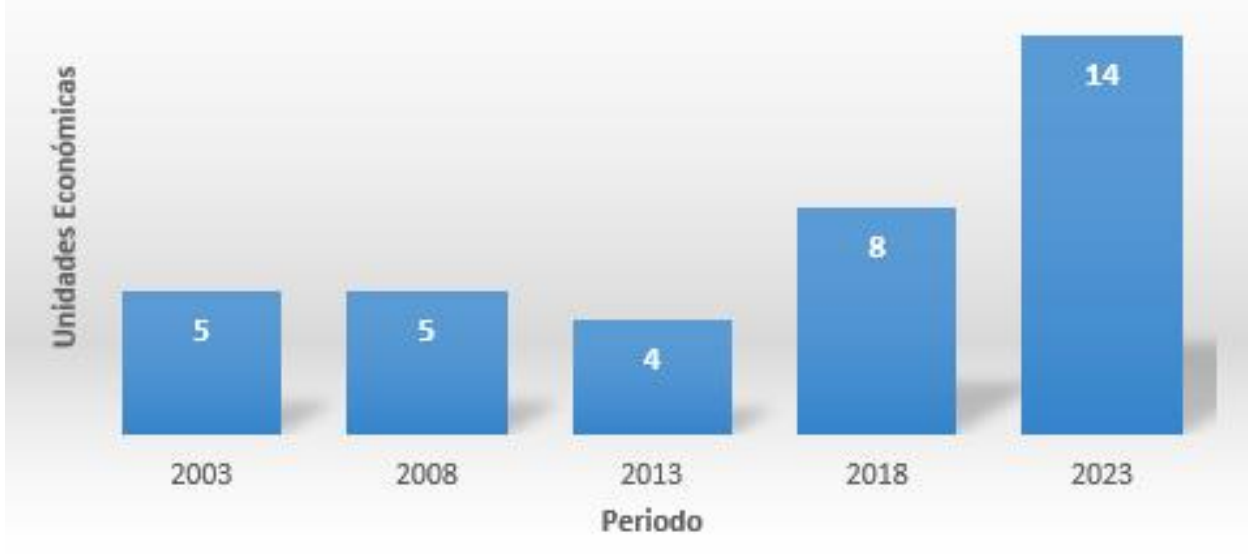

Del 2008 al 2013 pasó de haber 5 laboratorios a haber 4 respectivamente, ya que, en el año 2013 cerró un laboratorio por no cumplir con el reglamento y protocolo de calidad y salubridad necesaria.

Del año 2013 al 2018 se incrementó de 4 a 8 laboratorios en Mexicali y de 21 a 30 laboratorios en Baja California.
De igual manera incrementó significativamente los ingresos por laboratorio, ya que, la demanda también incrementó.

Del año 2018 a 2023 se estima que las unidades económicas de laboratorios incrementen $150 \%$, ya que, la demanda está forzando que se oferte un mayor número de servicios de laboratorio.

Figura 4.- Estimación de la Demanda de Posibles Clientes en el año 2018 en la Ciudad de Mexicali, B.C.

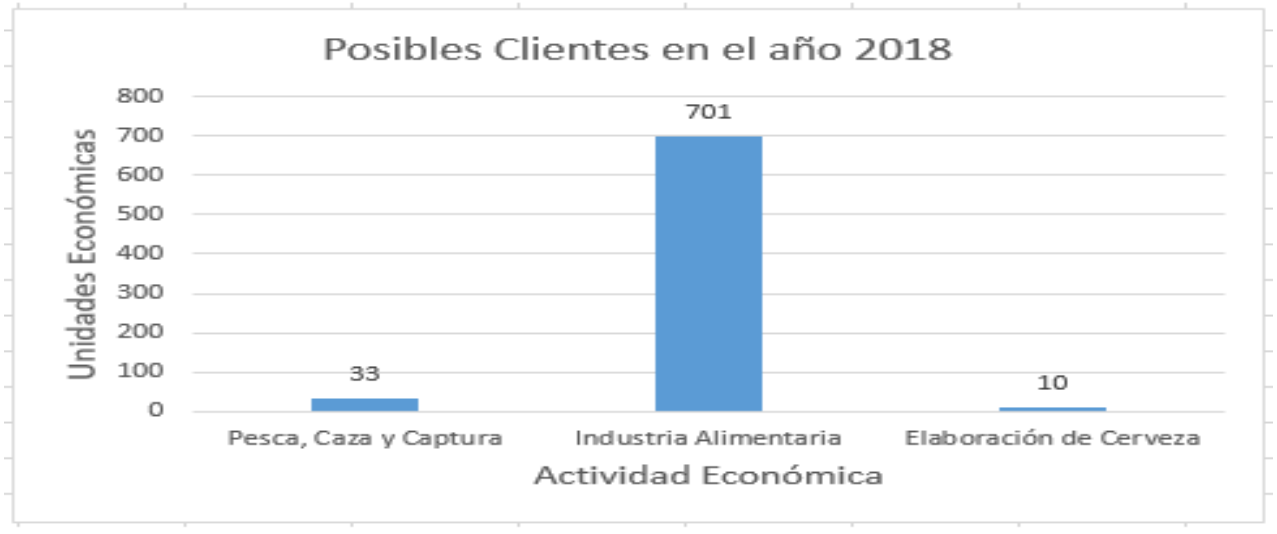

Después de analizar por medio del Directorio Estadístico Nacional de Unidades Económicas (DENUE) se tuvo un resultado de
747 posibles clientes que quieren demostrar la calidad de sus productos pero que no tienen la forma de realizarla ya que no hay laboratorios 
cercanos acreditados, los posibles clientes son de actividades económicas referentes a la agricultura, cría y explotación de animales y todo lo referente a la industria alimentaria.

Figura 5.- Entrevista a Microempresarios

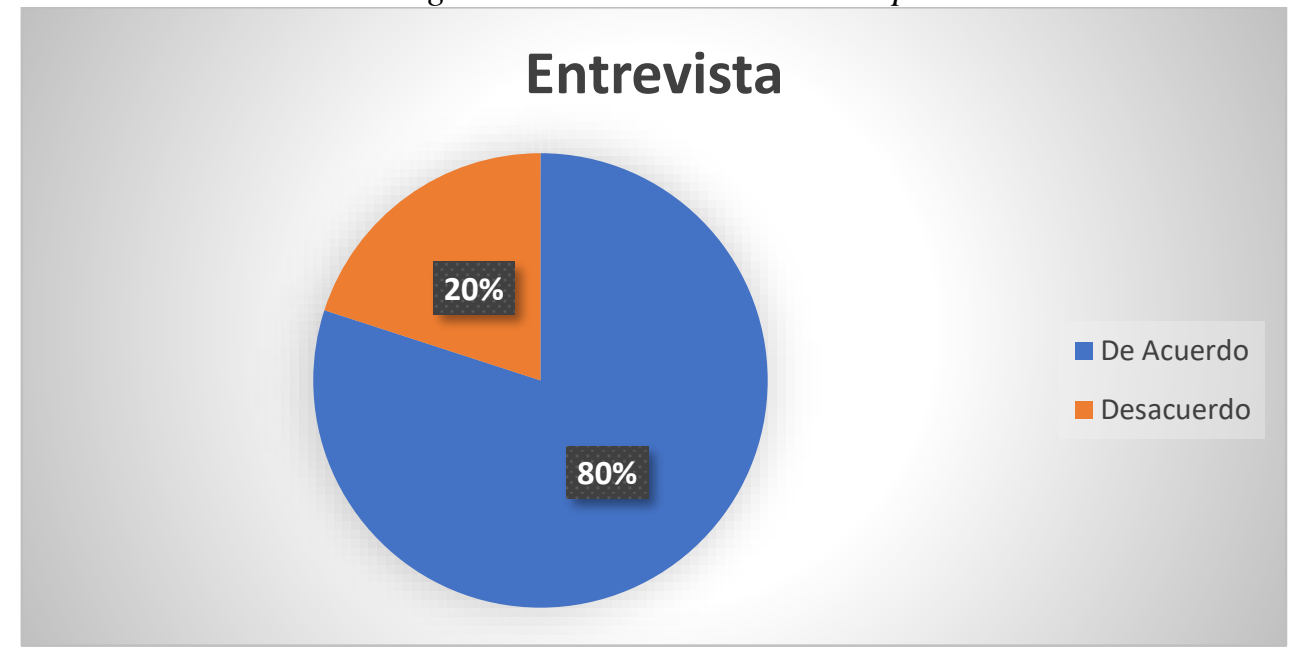

Los datos recabados en la figura 4 muestran una entrevista realizada a 40 microempresarios en el cual se llega al resultado que el $80 \%$ está de acuerdo en realizar análisis químicos a sus productos para corroborar que contiene dicho producto y de qué calidad; el $20 \%$ no está de acuerdo.

\section{CONCLUSIONES}

Gracias a la aportación por parte de la Encuesta sobre el Impacto Generado por COVID-19 en las Empresas realizada por INEGI en el año 2020, se llega a la conclusión que la pandemia afectó y sigue afectando a la sociedad en general y en especial al sector económico como por ejemplo a los establecimientos micro, pequeños y medianos.

Dichas empresas que tienen la necesidad de ofrecer ese diferenciador y poder seguir adelante tienen como opción y en cierto modo la obligación de ofrecer productos de mayor calidad y para poder justificar dicha calidad en alimentos es necesario acudir a un Laboratorio Acreditado que ofrezca el servicio de análisis químicos de alimentos y productos industriales.

Contar con una buena alimentación es de suma importancia y vital en todas las etapas de la vida, por esa razón es necesario escoger alimentos que cuenten con la mayor calidad posible. 


\section{REFERENCIAS}

Directorio Nacional de Unidades Económicas (2019, noviembre). Censos Económicos 2014;

Instituto Nacional de Estadística $y$ Geografía. INEGI. https://www.inegi.org.mx/app/mapa/denue/default.aspx

INEGI. (2020). EL INEGI PRESENTA RESULTADOS DE LA SEGUNDA EDICIÓN DEL ECOVID-IE Y DEL ESTUDIO SOBRE LA DEMOGRAFÍA DE LOS NEGOCIOS 2020. COMUNICADO DE PRENSA, 617/20, 3.

EMA. (2021). Entidad Mexicana de Acreditación. https://www.ema.org.mx

SCINCE (2020). Población Económicamente Activa. https://gaia.inegi.org.mx/scince2020/

Censos Económicos.

https://www.inegi.org.mx/app/saic/default.htm

DISTECO (2017). La Importancia de la Calidad en los Alimentos. https://disteco.com/la-importancia-de-la-calidad-de-los-alimentos/

PERIAGO (2018). Elementos de Trabajo en un Laboratorio Bromatológico. https://www.um.es/nutbro/docs/hica/Practica_de_material.pdf

GILSA (2021). Laboratorio de https://gilsa.com.mx/index.php/es/laboratorios/bromatologia

LICA (2021). Laboratorio Industrial de Control de Alimentos. https://www.lablica.mx/

ROCA (2018). Laboratorio Industrial ROCA.

https://www.laboratorioroca.com/

EMA (2015). Entidad Mexicana de Acreditación.

https://www.ema.org.mx/portal_v3/index.php/queesem

Díaz (2017). Manual del Laboratorio de Bromatología.

https://www.uv.mx/pozarica/cba/files/2017/09/MANUAL-DE-BROMATOLOGIA-2017.pdf

Proquideza (2015). Las ventajas de tener un Laboratorio Acreditado.

http://www.proquideza.com/ventajas-laboratorio-acreditado/

Secretaría de Economía (2009). Anteproyecto de Norma Oficial Mexicana PROY-NOM-051SCFI/SSA1-2009, Especificaciones generales de etiquetado para alimentos y bebidas no alcohólicas preenvasados-Información comercial y sanitaria.

https://members.wto.org/crnattachments/2009/tbt/mex/09_3029_00_s.pdf

Valdes (2019). La importancia de la NOM 051, encargada de regular lo que comemos.

http://misaludhoy.mx/la-importancia-de-la-nom-051-encargada-de-regular-lo-quecomemos/\#: :text=La\%20importancia\%20de\%20la\%20NOM\%20051\%2C\%20encargada\%20de,p oblaci\%C3\%B3n\%20infantil\%2C\%20podr\%C3\%ADa\%20padecer\%20este\%20tipo\%20de\%20enfe rmedades. 
